that the presence of a sufficient proportion of nickel will maintain the iron in the face-centred cubic lattice of the gamma phase at a temperature at which, in the absence of nickel, the iron would have reverted to the body-centred cube of the alpha phase. Presumably the iron remains in the gamma condition because in that condition it can retain a larger proportion of nickel atoms on the lattice, and because this arrangement involves less potential energy than any alternative. In the same way it was thought that the usual facecentred cubic lattice of copper might, when in the presence of more zinc atoms than can be carried on that lattice without undue distortion, be transformed into another lattice-still essentially a lattice of copper -but capable of carrying a larger number of zinc atoms, and that at a still higher concentration of zinc a further modification of the lattice might occur. Each successive modification would, in such a case, be expected to show an increasing approximation to the hexagonal lattice of zinc itself. Actual determinations of the lattices of the beta and gamma phases of the copper-zinc system, made by Owen and Preston in consequence of this suggestion, have completely verified it. The two phases show no compound lattice, but a modified copper lattice.

Another point of some interest in the distinction between solid solutions and compounds may be briefly considered. A good deal of consideration has been given by Tammann ${ }^{2}$ to the chemical properties of solid solutions, Tammann's work being based on the idea of a substitution structure, but without reference to lattice distortion. If this principle is applied, however, an interesting conclusion may be drawn, to which attention was first directed by Mr. Preston, in regard to what may be termed "symmetrical" solid solutions. In any alloy system forming a continuous series of solid solutions between two metals, alloys must occur in which the two kinds of atoms are present in some simple ratio such as one to one, two to one, three to one, etc. According to the particular nature of the lattice system in each case, some of these simple ratios will allow the atoms to arrange themselves in a perfectly symmetrical manner. Such perfectly symmetrical atomic arrangement, however, is not likely to be attained or approached except in specially favourable circumstances. Very gradual cooling from fusion and a considerable rate of diffusion are essentials, but there is the further condition that the symmetrical arrangement in question should be a simple one. Thus in any lattice, an arrangement in which alternate

" Tammann, Zeitschr. f. Anorg. u. Allgem. Chemie, July 19rg. layers or planes of atoms consist each exclusively of one kind of atom would seem to be such a simple arrangement. In the face-centred cubic lattice a oneto-one ratio allows of such an arrangement, all the atoms at the cube corners and those at the centres of two opposite faces being occupied by one kind of atom and the remaining four face-centres by the second kind of atom. In such a lattice, another simple symmetrical arrangement, but one less easily formed by the process of diffusion required by the present theory, is that in which all the face-centres are occupied by one kind of atom and all the cube corners by the other, this implying an atomic ratio of three to one.

The special interest which attaches to such perfectly symmetrical arrangements is that, if fully attained, there will be in such a lattice a perfectly uniform atomic spacing. The consequence must be, if the present theory is correct, a single melting-point and relatively low hardness and electrical resistivity. In some alloy systems, this state of affairs is so closely approached that it becomes plainly visible on the equilibrium diagram as experimentally determined, and the presence of a compound at the simple atomic ratio in question has sometimes been inferred-wrongly, according to the present view. In other systems, where diffusion is slow and uniform geometrical arrangement, therefore, is practically unattainable, the ideal condition is never reached experimentally, but the "solidus" curve shows an inflexion towards the "liquidus" in the neighbourhood of the "symmetrical" composition-in several examples near the one-to-one ratio of atomic concentration. In some alloy systems two such inflexions, corresporiding approximately to two such ratios, have been observed. Although these inflexions have become increasingly definite in the best-determined diagrams, so that they could not be ascribed to experimental error, no explanation has as yet been offered. The fact that these details are only to be seen clearly in recent diagrams, prepared by methods of extremely slow cooling of the alloys, tallies well with the requirements of our theory.

Inferences from the substitution and lattice-distortion theory could be pursued at much greater length; so far, no failure of such an inference, when tested by means either of older well-established fact or by special experiments, has yet been found. There is thus some hope that a small but real step has been taken towards the better understanding of the nature of alloys, and particularly of solid solutions and intermetallic compounds.

\title{
Weather Influences in the British Isles.
}

\section{By C. E. P. Brooks.}

THE sun is the only source of terrestrial weather in the sense that the difference between the amount of solar radiation received in different latitudes is the driving force of the atmospheric circulation. The complexity of the earth's, surface combined with its rotation about an axis introduces corresponding complexities into this circulation, but $\mathrm{H}$. H. Clayton considers that "if there were no variation in solar radiation the atmospheric motions would establish a stable system with exchanges of air between equator and pole and between ocean and land, in which the only variations would be daily and annual changes set in operation by the relative motions of earth and sun; the existing changes we call weather have their origin chiefly, if not entirely, in the variation of solar radiation." It has been found that some parts of the 
earth, especially the tropics, respond readily to these solar variations, while in other parts the solar variation is almost completely masked by secondary modifications. Hence we may classify weather influences into two classes: solar, in which the influence of solar variation is directly recognisable, and terrestrial, depending on causes which at first sight are entirely due to the influence of the land, sea, or atmosphere. These two classes shade into each other, with no definite line between them.

The weather of the British Isles, apart from seasonal temperature changes, is almost entirely terrestrial in its control, being dependent on the distribution of pressure over the North Atlantic and Arctic Oceans and the continent of Europe. This distribution is constantly changing, and we experience a succession of "depressions" and "highs" which pass across or near these islands, bringing our notoriously variable weather. Careful examination of a series of daily weather charts shows, however, that the most rapid changes are generally only in details, the main features of the pressure distribution changing comparatively slowly, and four main types of weather have long been recognised. These are named after the cardinal points whence blow the winds characteristic of the typesoutherly, westerly, northerly, and easterly.

In the southerly type, pressure is high over Europe and low over the North Atlantic. Depressions are continually appearing over the ocean, but their centres fail to reach the British Isles, so that we are situated between a depression to the west and an anticyclone to the east, a condition which brings southerly winds and warm weather. The amount of rainfall depends on whether the high or the low pressure predominates over the British Isles; it decreases from west to east. In the westerly type, pressure is high in the south and low in the north, and depressions appear from the Atlantic and pass rapidly eastward, generally along a track somewhat to the north of Scotland. This type brings fresh westerly winds; spells of a day or two of very fine weather alternate with spells with more or less rain, the actual amount being least when the storm tracks lie farthest north. If in addition to high pressure to the south an anticyclone develops over Iceland, with a trough of low pressure between, the depressions pass directly across the British Isles and very rainy weather is experienced, sometimes with destructive gales. On the other hand, when the southern anticyclone extends so far north as to include Great Britain, very fine weather is experienced, which, if prolonged, as in I92I, may give rise to a serious drought. A moderate development of the westerly type forms about seventy per cent. of our weather.

The northerly and easterly types are more or less reversals of the southerly and westerly types; the easterly type proverbially brings us our most unpleasant weather. These weather types may persist for periods varying from a few days to weeks, and unfortunately there is generally little means of knowing, when a type first becomes established, how long it is likely to continue. Some cases are more favourable, notably the formation of a large anticyclone centred directly over the British Isles. In such a case a long spell of fair weather is very probable, and when this distribution was established on September 26, I92r, a long-range forecast of fair weather for the next fortnight over eastern and central England was issued by the Meteorological Office, and was justified by results. The original division of weather into four types has been extended by the critical analysis of long series of daily weather charts, the most recent classification being that made by $\mathrm{E}$. Gold, ${ }^{1}$ and much material is now available for statistical study.

An understanding of British weather depends on an understanding of the causes which lead to the establishment and modification of weather types. We may carry the study a step further by referring to the conflict between "polar" and "equatorial" air, envisaged by the Norwegian meteorologists in their researches on cyclones; but a better insight into ultimate causes is given by the older conception of "centres of action," according to which the dominant factors in the pressure distribution are three : the area of low pressure which is generally found in the neighbourhood of Iceland or southern Greenland, and is termed the Icelandic minimum; the area of high pressure which occupies the eastern Atlantic near and south of the Azores, termed the Azores anticyclone; and in winter, the area of high pressure which is centred in Siberia and extends in a west-south-westerly direction towards the Azores anticyclone.

If we could forecast the position and intensity of these three centres of action during any month, we should be well on the road to true long-range weather forecasting. That is not yet the case, but a certain amount of information has been gleaned which encourages further research. The Siberian winter anticyclone appears definitely to be due to the extreme "continentality" with jts low temperatures and hindrance to the outflow of air ; it is, in fact, a "pool" of cold air. Such a continental anticyclone itself intensifies the cold of winter, and once formed is difficult to dislodge. There is nothing more favourable to the establishment of anticyclonic conditions than a covering of snow, and an extensive snowfall over northern or eastern Europe early in the winter may cause a persistent westerly extension of the Siberian anticyclone, influencing the weather of the British Isles for several months.

The other two centres of action are still more important, and they are intimately connected with each other. When pressure is high at the Azores it is generally low near Iceland, and vice versa; when the Azores anticyclone advances northward the Icelandic minimum generally does likewise, but there are exceptions to both these rules. There have been cases, notably February $\mathrm{x} 895$, when the distinction between the anticyclone and the depression was wiped out, and for a whole month pressure was higher at Iceland than at the Azores. The existence of these two centres of action is connected in some way, not yet fully understood, with the general circulation of the atmosphere, but there can be no question that the details of their position and intensity are modified by local effects, and especially by variations of sea temperature, and in the case of the Icelandic minimum by the presence or absence of floating ice, and we

1 London, Air Ministry, Meteorological Office. Geophysical Memoirs, No. I6. Aids to forecasting: types of pressure distribution, with notes and tables for the fourteen years, 1905-rg18. By E. Gold. London, 1920.

NO. 2823 , VOL. I I 27 
have to broaden our survey to include these two factors.

The primary facts about the circulation of the waters of the North Atlantic Ocean are familiar to most people, and for our purpose can be generalised into two processes. First, a great mass of warm surface water is driven westwards near the equator by the Trade winds, ultimately being deflected northward by the coast of America and forming the Gulf Stream ; secondly, this warm water is spread out south-east of Newfoundland, and is driven eastward by the prevailing winds towards the European coast. Consequently, any increase in the strength of the Trade winds should be followed after a considerable interval by a rise in the temperature of the sea north of Scotland. This has very little direct influence on the temperature of these islands, but it intensifies the Icelandic minimum and draws it south-eastward, causing low pressure and much cyclonic activity in the North Sea, with strong south-westerly winds over Holland, Germany, and Denmark, and northerly winds over Iceland. Thus, P. H. Gallé ${ }^{2}$ found that when ships' observations showed an increased strength of the Trades during spring and summer, the following winter was warm over Holland and Germany, but cold over Iceland and Greenland. This refers to observations over the whole Trade belt. Unfortunately, direct observations of the strength of the North-east Trade are difficult to obtain, but we may employ instead the mean pressure at the Azores, which may be taken as a measure of the development of the North Atlantic anticyclone, with which the Trade wind is associated. The interval between the occurrence of high pressure at the Azores and of low pressure near the Faroes is about a year, which is the average time required for the completion of the oceanic circulation between these points.

The influence of floating ice on the pressure distribution is equally marked. The great ice-factory of the northern hemisphere is the Arctic Ocean north of the Eurasian coast, and delivery is effected by a current which sets from near Spitsbergen down the east coast of Greenland and round Cape Farewell. Each spring this current carries great masses of seaice, and in some years with strong north-westerly winds much of this ice is carried to the coasts of Iceland. From rgor to r9I9 there were 43 months during which ice lay off Iceland for more than five consecutive days, and in the majority of these months pressure in Iceland was more than $2 \mathrm{mb}$. above normal. The mean deviation of pressure from normal during the whole of the ice-days (to the number of $70 \mathrm{r}$ ) was $+6.7 \mathrm{mb}$. Since there is no reason to suppose that the high pressure brings the ice, this result indicates conclusively that the ice and the cold surface water associated with it are effective in raising the pressure over Iceland and producing a northerly type of weather in the British Islands.

W. Weise ${ }^{3}$ has recently made a further step. The ice takes about $4 \frac{1}{2}$ years to travel from the Arctic Ocean north of Siberia, where it is formed, to the

${ }^{2}$ On the relation between fluctuations in the strength of the Trade winds of the North Atlantic Ocean in summer and departures from the normal of the winter temperatures in Europe. Amsterdam, Proc. R. Akad. Wetenschap, vol. 18, No. 9 .

vol. 18, No. 9. atlantische zyklonale Tätigkeit. Berlin, Ann. Hydrogr., vol. 50, 1922, p. $27 \mathrm{r}$.

NO. 2823 , VOL. I I 2 ]
East Greenland current, and he found that low temperature at Obdorsk and Turuchansk in autumn is followed after this interval by a large amount of ice east of Greenland, and vice versa. Thus an important factor in our spring weather is determined by conditions $4 \frac{1}{2}$ years previously in the north of Siberia.

The influences which control British weather are many and diverse, and it is not wonderful that the small fluctuations of the solar constant elicit no obvious response. Yet they can sometimes be traced; for example, at times of increased solar radiation (and many sunspots) the tracks of depressions appear to be on the average rather further south than with diminished radiation (and few sunspots). From 2 to $4 \frac{1}{2}$ years after sunspot maxima the Azores anticyclone tends to spread northward in summer over Spain and the Bay of Biscay, or even over the British Isles, giving conditions favourable to drought. Various other solar effects have been suggested in British weather, but none are definite enough for use in forecasting. The same conclusion must apply to " weather cycles." The search for the golden cycle in weather is curiously similar in its history to the search for the philosopher's stone-it has not been found, and we are more and more compelied to the belief that it does not exist; but in the search for it much information of value in other respects has been acquired. Periodicities in weather there undoubtedly are, but they are usually either so small in amplitude as to be of academic interest only, or they show baffling changes of phase and amplitude. Even the classical "Brückner cycle" of 35 years is only recognisable when we add the rainfall of ten consecutive years together, and its absolute uselessness for forecasting is shown by the position of the dry year $\mathrm{x} 92 \mathrm{x}$-one year before a maximum. The standard deviation from normal of a month's rainfall in London is about sixty per cent., while the variation attributable to the Brückner cycle is less than three per cent. A similar criticism applies to Sir William Beveridge's periodicities in the price of wheat.

Ocean currents and floating ice are thus the most important factors in British weather. Given a foresight of these two elements, we could make a reasonable guess at the general type of weather likely to prevail, though not the changes from day to day. Both ocean currents and ice are themselves also subject to modification by pressure distribution, and consequently we have a chain of cause and effect connecting a succession of months or seasons. We know the normal oceanic circulation and the normal pressure distribution. If in a given month we knew also the deviation of pressure from the normal distribution, we should be able to infer the abnormalities which will be produced in the oceanic circulation and hence to calculate the pressure deviations for the following month. If the process were sufficiently well understood we could carry our calculations forward long enough to give useful forecasts ; at present the subject has scarcely reached even the experimental stage. A large statistical basis is necessary, and it is only within the last few years that this has begun to be supplied by the Réseau Mondial, a compilation of monthly means of pressure, temperature, and rainfall over the globe.

- London, Meteorological Office, British Meteorological and Magnetic Year-Book, Part V. I9I0-I9r4 issued. 